\title{
Self-Knowledge and Self-Love
}

\author{
Jan Bransen
}

Accepted: 24 February 2015 / Published online: 14 March 2015

(C) The Author(s) 2015. This article is published with open access at Springerlink.com

\begin{abstract}
In this paper I argue for the claim that self-love is a precondition for self-knowledge. This claim is relevant to the contemporary philosophical debate on self-knowledge, but mainly because it draws attention to the role of claims of self-knowledge in the larger context of our ordinary practice of rationalizing and appropriating our actions. In this practice it is crucial for persons to open-mindedly investigate the limits of their own responsible agency, an investigation that requires a warm and gentle kindness to avoid both being too easy in welcoming and too merciless in resisting one's own imperfections as a minded agent. This kindness, I argue, is grounded in an evaluative relation of caring, a type of relation that is incompatible with selfhatred.
\end{abstract}

Keywords Self-love $\cdot$ Self-knowledge $\cdot$ Self-determination $\cdot$ Rationalization $\cdot$ Self-hatred Agential limits

When we rationalize our behaviour in ordinary everyday conversation, we do in a significant sense engage in projects of self-knowledge. This is not merely because we try to correctly report the mental states we are in, but also because we try to articulate the reasons for being in those states and - often in response to the questions of our interlocutors - because we intend to appropriate those reasons as our reasons, as reasons that really reveal some truths about ourselves. But self-knowledge does not come easy; an age-old platitude familiar since Socrates explained that to know thyself is the first and most difficult task for those who love wisdom. The advancement of contemporary scientific psychology has not relieved our predicament. Quite the contrary, or so it seems (Wilson 2002).

Part of the reason for this difficulty, as I argue in this paper, is that self-love is a precondition for self-knowledge, and it is self-love that is so hard to attain. If we want people to improve their self-knowledge we should encourage them to love themselves. Self-knowledge is not primarily the product of an epistemic relation between a knowing self and a known self, nor primarily the product of a rational relation between an expressive self and the accountable self spoken for. Rather, I argue, self-knowledge is the product of an existential and affective relation between a loving self and the self she loves to be.

J. Bransen $(\bowtie)$

Department of Philosophy, Behavioural Science Institute, Radboud University, PO Box 9104,

6500 Nijmegen, The Netherlands

e-mail: j.bransen@pwo.ru.nl 
The plan for the paper is as follows. In section 1 I discuss a small piece of ordinary conversation that involves questions of self-knowledge. Contrary to some dominant strands in contemporary analytic philosophy, I shall show that in such bits of conversation selfknowledge is not a narrow epistemic issue and is not about the actual mental state of the person in question. Rather, as I argue in section 2, when we talk about a person's selfknowledge, we talk about the person's capacity for reflexive self-determination, that is, their capacity for appropriating their thoughts and actions as their own. ${ }^{1}$ Such appropriation requires the person to open-mindedly investigate the limits of their own responsible agency, an investigation that itself requires a warm and gentle kindness to avoid both being too easy in welcoming and too merciless in resisting one's own imperfections as a minded agent. In section 3 I discuss the objection that my argument is vulnerable to the intelligibility of a person who hates themselves yet knows themselves. In response I argue that we have reason to believe that a truthful relation of self to self is grounded in an evaluative relation of caring, a type of relation that is incompatible with hatred.

\section{Self-Knowledge in Rationalising Behaviour}

As so-called non-epistemic accounts of self-knowledge have pointed out, bits of selfknowledge occur in ordinary conversations as part of the commonsensical routine to give reasons for one's state of mind. (Moran 2001) Here is part of such an ordinary conversation:

- I am sorry, Frank, but I think I have to cancel our meeting of today.

- Oh. Are you sure, Emma?

- Yes. I am afraid I am. It is my son's birthday tomorrow and I still have to buy him a present.

It is obvious for Emma that Frank does not ask her to closer inspect the content of her thought, as if he doubts whether Emma correctly reports what she thinks. Emma rightly understands Frank straightforwardly as inviting her to give him her reasons for her decision. Frank's question expresses his entitlement to an explanation of her change of mind. It would be weird for her to merely repeat the content of her thought, adding "really" to emphasize that she knows what she thinks. For Emma to know what she thinks means in such ordinary conversations to know her reasons for the state of mind she is in.

This commonsensical focus on a person's reasons for their state of mind can be used to clarify how a non-epistemic account of self-knowledge analyses the transparency and authority that are characteristic of self-knowledge. Emma's self-knowledge is transparent because she does not need to inspect her mind in order to discover the evidence she will use to infer the state she is in. She merely needs to inspect the reasons themselves. She thinks about her son's birthday, the present she still has to buy, the limited amount of time still available and the relative importance of her meeting with Frank. Weighing these reasons allows her to make up her mind and to determine the proper commitment to avow. Her self-knowledge is a feature of her being a rational, deliberative agent, not a feature of her capacity to introspect the contents of her own mind. Emma's deliberation also elucidates the authority characteristic of selfknowledge. She does not collect solid evidence to make a sound estimation of what she believes about her appointment with Frank. Her first-personal authority is not inferential, not a matter of the reliability of her introspective capacities, but is a matter of her being a

\footnotetext{
${ }^{1}$ My view of self-determination is influenced by Tugendhat 1986.
} 
deliberative agent, of her being in charge of her mind. Emma's self-knowledge is authoritative, because she is entitled to undertake commitments in her own name.

Frank's situation with respect to Emma's beliefs is, obviously, different. Epistemically speaking, Frank's perspective is third-personal. He does need the evidence. Rationally speaking, however, Frank's perspective is second-personal. He is not a somewhat displaced scientist who tries to read Emma's mind, but a rational companion inclined to invite Emma to share her reasons with him. Frank is a deliberative agent too, disposed to weigh Emma's reasons, not merely to determine the truth of Emma's belief, but to make up his own mind about their meeting, and thus to engage with her in practical reasoning.

For Frank to engage with Emma in practical reasoning is - by the same token - for him to engage with Emma's self-knowledge. Frank is not merely attending to Emma's reasoning as an impersonal exercise of a general human capacity, namely practical rationality, but as a personalized example of the particular way in which Emma's mind works. Here is a further unfolding of their conversation that might help to elucidate the point:

- Yes. I am afraid I am. It is my son's birthday tomorrow and I still have to buy him a present.

- I see. But, Emma, when we made this appointment last Friday you knew of course that it is your son's birthday tomorrow. So why didn't you plan to buy his present earlier? What went wrong?

Frank's questions will contribute to a shared attempt of him and Emma to exercise their practical reason. Frank asks for Emma's reasons to treat the reasons she mentions as sufficient for her conclusion to cancel the meeting. This might bring about an exchange of reasons that leads to the articulation of a tree of hierarchically ordered pro- and con-reasons, a tree that hopefully grows into a substantial set of reasons both accept as conclusively supporting Emma's decision to cancel their meeting. But it is unlikely and uncommon for this set to be an impersonal and decontextualized set of reasons. Frank asks Emma for her reasons in the present scenario. He wants to understand why Emma considers her reasons to be sufficient for her decision about their meeting later this day.

There are three issues at stake here. First, there is a question about the frame within which Emma's reasons may be conclusive for her decision to cancel the meeting. Frank seems to question Emma's reasons for treating this frame as an established fact. Emma may actually have no reasons for this, or at least, no reasons she paid attention to. Perhaps Emma just did not plan her days well enough, and has to acknowledge, with some embarrassment, that it is indeed a fact now that her son's birthday is tomorrow and that she has no present yet. If she would have been a more attentive person she might have considered this yesterday, as indeed Frank is suggesting. Perhaps her earlier negligence should be added to the balance of reasons which might then turn out to count against Emma's decision. Frank, we may say, is questioning the rationality of Emma's background narrative. This is the narrative that explains what it means for her to be a rational agent. This narrative employs Emma's implicit assumptions about the limits of her agential space, the depth of her moral luck, the degrees of freedom she enjoys and the scope of her need to take responsibility. (Wolf 2004) It is, for instance, just Emma's impulsive and procrastinating way of doing things that puts her and Frank in this uncomfortable situation that she now leniently tries to resolve by confronting Frank with what she suggests is an established fact.

This brings in a second issue. Emma is not merely presupposing the rationality of an isolated narrative of her own life, that depicts her as a particular kind of rational agent, but she is also attuning to Frank's style of reasoning. Part of her background story is a story about the specific agent she takes Frank to be. Emma apparently expects Frank to accept the frame of her 
reasons as a fact and the force of her reasons as conclusive. Emma may be right. There may be a history they share in which Frank has given her ample reason to think he is easy-going. No doubt Emma would not expect just anybody to accept her reasons for cancelling a meeting in this relaxed way. If she would know that Frank is a very rigid and neurotic person who needs a lot of stability and structure, she would surely have adapted her reasoning automatically to suit Frank's style of practical reasoning.

The third issue concerns the quality of Emma's assessment of the salient features of the scenario as they strike her within the frame she mindlessly assumes to be in place. We don't know that much about Emma, Frank and their relationship based on this short conversation, but we might plausibly infer that their meeting is not an event of great importance. It seems not much of a serious appointment given that Emma thinks it can be cancelled one-sidedly. Should it have been a job interview or their first meeting after an amazing one-night stand, it would be quite unlikely that Emma would introduce her son's birthday present as a potentially sufficient reason for cancellation. Their meeting is clearly a casual event, likely to be easily replaceable by another one.

To summarize, Emma's rationalisation reveals bits of self-knowledge because it builds on her implicit assumptions about (1) the basic narrative of her life as lived by the kind of agent she is, (2) the rational requirements she and her interlocutors are inclined to respect, and (3) the saliency of particular features of the scenario she finds herself in.

Emphasizing these issues allows me to clarify the distinction between self-knowledge as it is commonsensically understood by ordinary people and as it is often discussed in contemporary analytic philosophy. Philosophers tend to focus on the single, occurrent state of knowing the content of one's actual mental state. This implies a serious exclusion on two sides of the self-relation. On the side of the knowing self philosophers tend to restrict their attention to the current subject of a single belief, the actual entity referred to by "I" in a self-report at the moment of its expression. Thus, in the case of Emma the knowing subject is considered to be the actual reflecting person, Emma, who has made up her mind in deliberation and who is now in a mental state of entertaining (as philosophers call this) the balance of reasons for and against cancelling her meeting with Frank. Focusing thus exclusively on Emma's current reflective state of mind is likely to neglect the role of Emma's tacit knowledge of the background assumptions that co-determine the balance of reasons in important ways.

On the side of the known self philosophers tend to restrict their attention to the explicit propositional content of the mental state reported by the reflecting person. In Emma's case this is the mental state she is in in virtue of her deliberately having settled the issue of whether or not to cancel her meeting with Frank. Focusing thus exclusively on the propositional content of the mental state that concludes Emma's deliberation, and that Emma reports as the state she is in, is likely to neglect the rich significance of the narrative background against which Emma's decision stands out as meaningful.

However, the ordinary understanding of a person's self-knowledge is quite different: it is a person's general capacity to be in tune with herself, to know what kind of person she is and thereby to understand, and to endorse, the mental state she finds herself to be in. Selfknowledge is for ordinary people not the isolated surface phenomenon of being able to speak one's mind, but rather the grasp of the implicit background narrative, of the rich content of one's own autobiography that is tacitly assumed by someone who is "at home" in her own life. Incidentally, "home" can be used here by analogy to explain the difference between a 'subject matter' and the 'instant object of a single belief'. If I say that I know my brother's home it is very unlikely that I have seen it only once. "Home" is not a word used to refer to the instant object of a single belief, but rather a subject matter with which I am well acquainted, both over 
time and affectively. ${ }^{2}$ The same is true about the way in which ordinary people use the word "self". Someone who knows herself is not an isolated subject who is capable of accurately reporting only once the propositional content of the current mental state she is in. Knowing oneself implies being well acquainted, both over time and affectively, with the key features of the narrative of one's life. It is a matter of knowing the protagonist of one's biography, the person living one's life.

This means that the self-knowledge Emma displays by rationalizing her behaviour in this specific conversation with Frank, is much more than merely an epistemic relation between a knowing self and a known self. It is also much more than merely a rational relation between an expressive self and the accountable self spoken for. It is primarily, as I shall argue in the next section, an existential and affective relation between a loving self and the self she loves to be. I shall elaborate on this by discussing two alternatives of Emma. ${ }^{3}$

\section{Rationalisations: Lovingly Embracing One's Limits}

In the previous section I have introduced Emma and Frank, two people engaged in a rationalising conversation. One of them, Emma, reports a change of mind. ${ }^{4}$ Whereas she initially intended to meet Frank this afternoon, she now wants to cancel their meeting. Frank asks her whether this is what she really wants, which is not a narrow epistemological question, but primarily an invitation to engage in a joint deliberation. That is, Frank's question is primarily an expression of Frank's entitlement to expect Emma to give him her reasons for not keeping her appointment. Emma, therefore, does not merely need reasons to justify her change of mind to herself, but she also needs reasons that are strong enough to expect Frank to grant her this change of mind even though this may be a disappointment to him. ${ }^{5}$ Although the situation is obviously not heavily moral, it seems to fit the moral scheme of Emma owing Frank an explanation that he might have reason to consider unsatisfactorily.

This scheme of one person owing another person an explanation will prove useful to elucidate the structure of the self-relation characteristic of self-knowledge. To that end I shall introduce two alternatives of Emma that differ in their inclination to examine the limits of their agential space, that is, the scope of their commitment to take responsibility. For reasons that will emerge from my discussion I shall call them Evasive Emma and Truthful Emma.

Remember Frank's uncomfortable question:

- I see. But, Emma, when we made this appointment last Friday you knew of course that it is your son's birthday tomorrow. So why didn't you plan to buy his present earlier? What went wrong?

Now this is how Evasive Emma responds:

\footnotetext{
${ }^{2}$ This seems to be a convincing observation whatever the ontological commitments implied by our preferred account of personal identity. Cf. Holton 2001, 55-6.

${ }^{3}$ I am building here on earlier work on the concept of an alternative of oneself. See Bransen 1996, $2000,2008$.

${ }^{4}$ Although the emphasis in my argument shall be on changing one's mind, the fact that a change is involved, does not restrict the plausibility of the argument to cases of self-knowledge that involve a change. One can of course also know one's stable convictions, but in such cases my argument will apply too, in the other direction, as it were, as involving reasons not to change one's mind.

${ }^{5}$ We can imagine situations in which Frank is sensitive to different reasons than Emma. However, this does not play an important role in the argument of the next section, where I shall treat Frank as somehow merely a stand-in to emphasize that Emma needs to appreciate her own reasons from an outsider's perspective.
} 
(EE) - Well, I did plan to buy the present yesterday. But a colleague at work needed my attention. She was a real pain in the ass, absorbing all my time. That wrecked me. I just couldn't reach the shopping mall before closing time.

And this is Truthful Emma's response:

(TE) - Well, buying the present was on my mind yesterday. But I had a bad day. A colleague complained about my work, and I guess she was right, which was rather embarrassing. It took away all my energy, so I went home early. I'm sorry.

I am aware of the fact that the possibly poor quality of these fictional replies and their specific details might be an obstacle to the force of my argument. But I take this risk because the argument needs the context of ordinary life and of commonplace excuses.

Evasive Emma does not seem inclined to acknowledge that she has an obligation to apologize for her change of mind. She appeals to an externalizing story that tells itself as a sequence of events, events that happen to her and that simply overrule her willingness to meet with Frank. Despite her good intentions, the world just does not cooperate with her on this occasion. Evasive Emma invokes a quasi-objective perspective that seems to suggest that any reasonable person would have come to the same conclusion. There is nothing special or noteworthy about her. It is only to be expected that Frank will agree that the balance of reasons constrains her in this scenario: there is simply no other option available to her but to cancel their appointment. Evasive Emma suggests that the way the world is gives her a compelling excuse for her change of mind, as if she is really precluded by outside forces from meeting with Frank. She made up her mind, but she did so in this purely outward-looking way by paying attention to the rational force of the salient features of the scenario she found herself in. It would be inappropriate for Frank to be disappointed about her. If he is disappointed he is bound to confirm that she will be disappointed too, disappointed about the world that did not offer her any degree of freedom. Evasive Emma's story implies that it is futile to request her to take responsibility for her decision to cancel their appointment. She is obviously willing to do so, if pressed, but she had no choice. There was no reasonable option to do otherwise.

Truthful Emma's story is different. She apologizes to Frank without trying to use the way the world is to excuse herself. She personally feels sorry and responsible for changing her mind. She has her reasons, but she definitely recognizes that Frank may find these reasons wanting. She offers her personal perspective on the scenario she found herself in. She acknowledges that her reasons have much to do with her take of things, not merely in the sense of her having to take responsibility for weighing these reasons but also in the sense of her being a sentient, emotional being who is affected by the way the world confronts her and who has limited resources. She feels rather confident that Frank will agree with her because the balance of reasons she considered seems to provide her with a pretty reasonable excuse to cancel their meeting. But she acknowledges that she changed her mind and that Frank may be disappointed. And rightly so. She seems willing to live with that. Truthful Emma seems to endorse her reasons as if they offer herself a justifying excuse, that is, an excuse she may grant herself, self-consciously, even though she acknowledges too that Frank doesn't owe her to grant her this excuse.

I introduce Truthful Emma and Evasive Emma to explore opposite tendencies we may distinguish in Emma's dedication to self-knowledge. That is, I introduce these alternatives in an attempt to identify different directions on a continuum between, in one extreme, Emma's absolute commitment to know herself and, in the other extreme, Emma's absolute attempt to mask, conceal or obscure herself. In addition to this argumentative artifice I should like to use the interpersonal conversation between Frank and Emma as a frame for Emma's 'conversation' 
with herself, that is, for her reflexive endeavour to articulate and endorse the reasons she takes herself to have for justifiedly making up her mind the way she does. This means that the picture I should like to suggest is that in exploring the responses of Truthful Emma and Evasive Emma to Frank's challenge I offer an elucidating analogy for Emma's self-relation as either contributing to a growth of self-knowledge or to a decrease of self-knowledge. The argument, thus, invites you to imagine what Emma would think of herself if she, rather than Frank, would be the addressee of Truthful Emma's and Evasive Emma's replies to Frank's questions.

Truthful Emma is paradigmatically motivated to know herself. That is, she is reflexively interested in knowing what makes her make up her mind in the way she does. Note the double level. Truthful Emma has her reasons, and she knows they count in favour of cancelling her meeting with Frank. But in addition to acknowledging the normative import of these reasons, Truthful Emma is interested in knowing what makes these reasons her reasons, or stated the other way around, what makes her appreciate these reasons as sufficiently accounting for her change of mind. This reflexive interest reveals that Truthful Emma is aware of the fact that in making up her mind she is relying on implicit assumptions about (1) the basic narrative of the life she lives given the kind of agent she is, (2) the rational requirements she and her interlocutors are inclined to respect, and (3) the salient features of the scenario she finds herself in.

What does this fact tell Truthful Emma about herself? How should she relate to it? What should she make of it? It is in responding to these questions that Truthful Emma will recognize that her reasons for self-love are crucial to her self-knowledge. Let me explain.

To begin with, Truthful Emma wants to own the decision to cancel her meeting with Frank. That is, she wants to identify herself $a^{6}{ }^{6}$ a person who actively makes up her mind, who intended to meet with Frank but now wants to cancel their meeting. Emma changed her mind, but for Truthful Emma this is not just an event that happens to her. It is a mental act for which she is willing to take responsibility. It is a change of mind that she undertakes and that she should be able to give her reasons for. The point is a familiar one for the non-epistemic, deliberative accounts of self-knowledge such as Moran's. A crucial feature of knowing one's own mind is after all the awareness of the fact that the mind one is supposed to know is one's own mind. And ownership is not merely a brute factual relation but a normative relation: it is a matter of the person having a certain status with respect to the mind in question. (Brandom 2000; Kalish 2005; Benson 2005) Whatever she encounters in her mind calls for a deliberate and reasoned response.

But in appropriating Emma's change of mind Truthful Emma will have to acknowledge that she treats the implicit background narrative about her life as a rational agent as offering her an excusatory justification for her change of mind. The idea is this. Emma's resources to rationally justify her change of mind are obviously limited. This is a global feature of her human condition, involving among other things her dependency on all kinds of physical and biological processes, her emotional vulnerability, and her cognitive, linguistic and communicative limitations. It is for Emma - as for every human being - simply impossible to fully rationally appropriate her own mind. Emma changed her mind, and she has reasons for it, reasons Frank might accept as sufficient. These reasons, however, consist to quite some degree in the recognition of Emma's limits. Her limitations frame the background narrative of her life as lived by the kind of agent she is. In everything she does and in every rationalisation she undertakes she implicitly assumes this background narrative. She revises it, for sure, adapting

\footnotetext{
${ }^{6}$ As I have argued in Bransen 1996, in matters of autonomous, responsible agency the preposition 'as' fits better with the verb "identify" than the much more common proposition "with". Using "with" suggests a problematic division within the person that is not needed to account for responsible agency.
} 
and accommodating it to the scenarios in which she enacts her life, but in many ways it will remain implicit and will uncritically reinforce limits that apparently will never be rationally scrutinized. It is unclear, however, how much the mindless reinforcement of these limits can carry by way of rationally justifying Emma's being in the state of mind she happens to be in. Truthful Emma will therefore know that she takes for granted that the background narrative of her life gives her an excusatory justification to conclude her rationalisations at some essentially contestable point. The existence of such a contingent limit is a crucial, defining feature of her being the kind of deliberating agent she is. ${ }^{7}$

In the case at hand, for example, Truthful Emma recognizes that the complaint of her colleague took away all her energy. Well... that might be a fact. But it is unclear in which sense this is a fact that gives Truthful Emma a reason to cancel her meeting with Frank, or a reason to expect Frank to accept this fact as a sufficient reason for Emma's decision to cancel their meeting. Truthful Emma could of course offer further support for her contention that the fact does indeed give her a sufficient justifying reason to cancel her meeting with Frank. But whatever she would add in support of her decision, there would necessarily come an end to her rationalisations. And having reached that end, Truthful Emma can only hope, trust or assume that the background narrative of her life will support her contention to treat her reasons as sufficient. This means, in the end, that Truthful Emma will have to accept that she cannot do more than she can. This does not necessarily mean that, in some absolute sense, she has done enough to justify her change of mind. Truthful Emma will have to acknowledge that in the final analysis the background narrative of her life as a rational agent might amount to nothing more than the bare excuse that, as Wittgenstein famously observed, "this is simply what I do." 8

Embracing her limits in this way is not a leap of faith. Truthful Emma is not embarked on a narrow epistemic or merely theoretically rational enterprise. Taking responsibility for the endorsement that she is right as a rational agent to cancel her meeting with Frank, is not merely a matter of accepting a proposition as true. Even though Truthful Emma is paradigmatically dedicated to know herself, I have already argued in section 1 that self-knowledge involves much more than merely an epistemic relation between a knowing self and a known self. Part of what more is involved is highlighted by non-epistemic theories that stress that selfknowledge crucially is a matter of avowal, of making true what is claimed to be true by acting on the balance of reasons that present themselves in the scenario at hand. But this balance is not, as we have now seen, merely an objective feature of the scenario an agent such as Emma finds herself in. The balance of her reasons is importantly co-determined by the background narrative that she implicitly accepts in making up her mind. Appropriating her decision as hers, therefore, entails Truthful Emma's acknowledgement that she accepts the responsibility to stand for an excusatory justification that her interlocutor, Frank, might have reason to consider insufficient.

Accepting this responsibility cannot be grounded in an impersonal and decontextualized set of reasons, but will be a matter of Emma's capacity to lovingly identify herself as Truthful Emma. The reasons Frank is asking Emma for are, for Emma, not merely the reasons that make her change her mind. They are also reasons the appropriation of which shows Emma's care for the person she could love to be. This is not a blind egocentric love. Truthful Emma's ambition to know herself requires self-love, but it does not mean that she needs to proudly and narcissistically recognizes herself to be a lovely person, someone who it is a delight to know. Quite the contrary. Real love implies a warm and gentle kindness to welcome and embrace

\footnotetext{
${ }^{7}$ Here and elsewhere in my exposition of reflexive self-determination I am influenced by Tugendhat 1986.

${ }^{8}$ Wittgenstein (1953/2001), Philosophical Investigations, 217.
} 
a person regardless of perceived weaknesses, flaws and imperfections. To be sure, these imperfections are not the reasons for Emma to love herself. They figure in her reasons to change her mind, and her appropriation of them as sufficient reasons for her change of mind discloses the self-love she needs to be true to herself about her imperfections. This is the kind of love Emma should be capable of, and it is the love Truthful Emma evokes by truthfully maintaining the delicate balance between being too kind and too harsh with herself, between being too easy in welcoming imperfections and too merciless in resisting them.

I have argued elsewhere that self-love essentially involves a concern for the quality of one's own attunement as an agent to the normatively significant features of one's environment. (Bransen 2006) I obviously cannot reconstruct this argument here, but hopefully a rough sketch of some of the highlights will do to explain the role of self-love in self-knowledge. Selflove is a feature of agents, living human beings that interact with their environment in ways that involve not merely the metabolic autopoiesis of living organisms but also a normatively structured self-regulation required for persons to maintain themselves in social and cultural environments. People's deep and natural drive to care for themselves is a motivational state that is much the same as what Frankfurt has analysed as the volitional necessity that is characteristic of love. (Frankfurt 1994, 2004) We cannot but care for the things we love. But importantly, loving ourselves is not a matter of acting out of self-interest. After all, besides volitional necessity love is crucially characterised by a deep disinterestedness. It is the wellbeing of the object of one's love that motivates the lover. Whatever it takes - the lover is willing to sacrifice themselves for the sake of the object of love. This creates special difficulties but also special opportunities in cases where the lover and the object of their love are one and the same person. Self-love, I argued, requires a rather peculiar kind of self-relation, one that implies the reflexive capacity to discern an alternative of oneself that presents itself as an alternative one is capable of loving. (Bransen 2006) The identification of such an alternative requires contrastive knowledge of the different ways of maintaining one's agency in a world that need not cooperate. Self-love, I argued, entails the capacity to distinguish between different alternatives of oneself and the affective experience of one's peace of mind in imagining oneself to be this rather than that alternative.

With respect to the argument of the present paper, this short sketch of self-love suggests that Emma, in responding to Frank's questions, should try to figure out whether she is capable of loving Truthful Emma or Evasive Emma. Exploring such contrasting alternatives is a familiar feature of self-determination. Think of such attempts to imaginatively project yourself into the future, to use Catriona Mackenzie's phrase, when you try to determine whether you want to pursue a career as lawyer or as musician, or whether you better think of yourself as a banker or a sheep farmer instead (Mackenzie 2008; Bruckner 2009).

In this section I have explored whether Truthful Emma evokes feelings of self-love in Emma, and I have tried to argue that she does. Truthful Emma is motivated to determine the contours of her responsible agency and this requires her to sincerely and open-mindedly investigate the limits of her own agency in a world that need not cooperate, a world that might ruthlessly reveal her weaknesses, flaws and imperfections. To know herself Emma should not shy away from facing her own limits and shortcomings as a rational agent. Emma therefore needs to love herself to appreciate Truthful Emma's reasons as her own, that is, to determine the characteristics of her agency, which includes embracing her background narrative and its essentially contestable rationalising force.

In the next section I shall explore whether Evasive Emma is capable of self-knowledge without a warm and gentle kindness towards herself. 


\section{Is Self-Love Really Necessary for Self-Knowledge?}

It may be objected that my argument so far merely supports the idea that selfknowledge presupposes that someone has an affective relation with oneself, but that it seems mistaken, or at least unwarranted, to claim that this relation should be a matter of love. The objection might take the form of accepting that Evasive Emma does not love herself - which I seem to have stipulated - but that it is unclear why she would lack self-knowledge. Evasive Emma might know that she went home early and that she did because she was painfully embarrassed by her colleague's complaint. She might know that her colleague was right about her failure to perform as well as she should, given the responsibilities of her job. She might even know that she lacked the energy and the mood to buy her son a nice present. And it even seems plausible why not? - that she knew all along that her failure to buy her son a present would imply that she would have to cancel her meeting with Frank. She might know all this, and precisely because of this self-knowledge, Evasive Emma might have been motivated to avoid reporting these truths, truths she knows but prefers not to share with Frank, perhaps even precisely in order to prevent the pain of one more confirmation that she is not worthy of her love. And, the objection might run, she even knows she is not worthy of her love, because she will disappoint Frank and even chooses to lie about that.

This might seem to be a psychologically plausible picture, perhaps even a convincing picture, so why do I make the ambitious claim that only Truthful Emma is authorized to know herself? Does my argument merely hinge on the question-begging use of the adjectives "evasive" and "truthful"?

Let me focus on Evasive Emma's alleged self-knowledge, by adding a confronting reply by Frank to his fictional conversation with Evasive Emma. Remember her original response:

(EE) - Well, I did plan to buy the present yesterday. But a colleague at work needed my attention. She was a real pain in the ass, absorbing all my time. That wrecked me. I just couldn't reach the shopping mall before closing time.

And here is Frank, pressing Evasive Emma to challenge her self-knowledge:

(F) - Nice excuse, Emma. But I have my limits, you know. This has been your pattern for years. You don't seem to take me serious at all. Just about any reason seems to be good enough for you to push me around. What do you think of me? And, beware, I don't want you to talk about me, now, but about how you talk about me. What do you think of yourself? What kind of person are you, given that you think it is okay to treat me like this?

Now suppose Evasive Emma bites the bullet and responds quite frankly as follows:

- To be perfectly honest, Frank, here is what I think of you and of myself. I think you are a weak and insignificant person whose feelings don't really matter. As for me: I am a proud, arrogant and self-involved person, convinced of my own superiority, even while I also can find my self-regard easily deflated by other people's negative comments. And I despise myself for all of this. ${ }^{9}$

\footnotetext{
${ }^{9}$ This response is suggested by an anonymous referee who was not convinced by an earlier version of my argument in this section.
} 
What should be in place to make this a conceivable reply that displays Evasive Emma's selfknowledge?

First, we should distinguish between a situation in which Evasive Emma overtly responds in this way to Frank and a situation in which she explicitly thinks of this reply but decides, for further reasons, not to be that sincere to Frank but to respond in a more shallow and concealing way. My argument, of course, cannot be built on merely the first type of situations. After all, as I said above, the interpersonal conversation between Frank and Emma functions merely as a frame for Emma's 'conversation' with herself. If Evasive Emma is capable of thinking in an articulated manner about the above response, it doesn't matter for her self-knowledge whether she chooses for additional reasons not to share her thoughts with Frank. But is she capable of formulating the above reply, and if she is, does this show she knows herself? What would it mean, for Emma, to know that everything she thinks here is true?

There are two issues that deserve attention. On the one hand Emma will have to face questions of coherency and on the other hand she will have to face questions of ambiguity. The objection claims that Evasive Emma has knowledge, knowledge of herself, and this means that the picture she has of herself should be coherent. This is an ordinary requirement for knowledge claims. Of course, the object one has knowledge of may be incoherent to a certain degree, but in such a case the incoherence should be a feature of the object, not of the propositions about the object. There are some ordinary limits to this possibility. Objects that are too incoherent lose their conditions of individuation and may turn out to be unintelligible. A tomato may be green and red, but not in the same spot at the same time. If you have knowledge of one tomato that is indeed both green and red your claims about the tomato's colour should be coherent and they should explain in which sense this tomato is both green and red. You cannot just claim that it is but you should add spatiotemporal indices to specify when and where it instantiates those colours. In Emma's case, this means that it may be possible that an incoherent set of propositions is true about her. It may, for instance, be true about her that she both believes that she is a helpless victim of an unpredictable world and believes that she is arrogantly using a false excuse because she is an irresponsible agent who does not care at all about other people's entitlements. But also in this case we would need indices in the propositions that articulate the knowledge to guarantee that the propositions form a coherent set. What indices could these be?

From Frank's point of view this need not pose a serious problem. Frank could simply think that Emma is incoherent, that she claims both to be a helpless victim and offends him by shamelessly admitting she doesn't care at all about his feelings. He may add a mood index, thinking that Emma at first cowardly tried to get away with her excuses and later overstated her self-regard due to her anger. In such a way Frank could have a coherent picture of an incoherent person. But what options are there for Evasive Emma? The difficulty, obviously, is that the coherency requirement for knowledge poses special constraints to instances of selfknowledge. The fact that the knowing self is the same person as the known self makes it quite difficult for someone to form a coherent set of claims that clearly articulate that there is no incoherence in this set of claims even though there is incoherence in the person who accepts these claims. If Evasive Emma really knows that everything she would want to say to Frank is true, then she should also know that her earlier reply was a false and lame excuse, and thus that she is not a helpless victim but a responsible agent with some degree of freedom. But if she knows that she is a responsible agent Evasive Emma needs to explain why she first tried to get away with a false excuse and why she responded with such a fury when Frank addressed her self-regard. She may add mood indices, but then, of course, if she claims to have selfknowledge, she needs to acknowledge the relevance of the right kind of mood for knowledge claims: an open-minded and sincere calmness to inspect, in an epistemologically virtuous way, 
the incoherence of her thoughts and actions. That is, if Evasive Emma explains her thoughts and actions in terms of her sensitivity to certain moods, she should wonder whether what she takes to be self-knowledge is itself also sensitive to one of her moods. Given that she is an ordinary human being, it is quite likely that she is sensitive to moods. But then she should at least wonder whether her self-hatred is the proper kind of mood for truthful and coherent claims of self-knowledge.

At this point questions of ambiguity arise, and they concern the issue of whether Evasive Emma is inclined merely to mask herself to Frank or also to herself. That she masks herself to Frank is clear. This is perhaps merely obvious in her first response, when she tried to put off Frank with a cowardly excuse, but it might also be true in her arrogant second response, in which her fury might preclude a clear view of the person Emma is. Interestingly, both her first and her second response apparently seem to suggest the same thing to her: that there is no reason for Evasive Emma to inspect the limits of her agential space. Yet the two responses are clearly contradictory with respect to where those limits are located. In ordinary cases such a contradiction would give Evasive Emma definitely a strong reason to at least wonder about the limits of her agential space.

So why doesn't she inspect the scope of her responsible agency? Evasive Emma can give multiple answers. She simply knows she is a bad person, so there is no need to highlight the obvious. Or she doesn't want to feel the pain of her blameworthiness. Or she doesn't want to blame herself again. Or it is just obvious that she won't get away with a really convincing excuse. Etcetera. All those answers strengthen the suspicion that perhaps Evasive Emma is masking herself not merely to Frank but also to herself, even in the case in which she merely considers the second reply in inner conversation. But if she is, the assumption that Evasive Emma has self-knowledge seems unwarranted, if not simply wrong because of the intrinsic ambiguity of her claims. Evasive Emma's self-hatred seems to motivate her to avoid the opportunity to potentially improve her self-knowledge by discouraging her to explore the limits of her responsible agency.

I take this to suggest that Evasive Emma's self-hatred motivates her to be too harsh to herself about the distinction between herself and her environment, which is just as bad for her self-knowledge as the narcissistic opposite of being too kind to herself about that distinction. ${ }^{10}$ For self-knowledge Emma needs a firm grip of the delicate balance between being too easy in welcoming imperfections and too merciless in resisting them, a grip Evasive Emma is unable to offer because she avoids striking this balance. But Emma needs it to know herself; that is, to determine the precise scope of her responsible agency. (Tugendhat 1986) And she needs selflove for her grip on this balance, the warm and gentle kindness to welcome and embrace her agential space, large or small as it may turn out to be given the person she is - a responsible agent with weaknesses and strengths, flaws and blessings, imperfections and virtues.

If she wants to know herself, therefore, Emma must love herself. In thus knowing herself she will acknowledge that she is not merely an epistemically motivated knowing subject nor a merely rationally motivated avowing agent, but an affective, loving self motivated to care for the agent destined to live her life. It is this self-love that is essentially characteristic of truthful self-knowledge. It is this self-love that is challenged (and reinforced) in ordinary conversations that - at the surface level - mainly seem to challenge our self-knowledge.

\footnotetext{
${ }^{10}$ The fact that self-knowledge needs the open-mindedness to avoid both vices can be used to explain the fact that sometimes people learn most from a gentle and caring environment whereas at other times they learn most from a harsh and direct confrontation with some unwanted truths about themselves. Thanks to Michael Kühler for pointing this out.
} 
Acknowledgments This paper has been in the making for too many years. I thank audiences in Oxford, Nijmegen, Rotterdam, Leusden and Modena for their helpful comments on predecessors of the present paper, especially Martin Weichold, Nicole van Voorst Vader, Fleur Jongepier, Michael Kühler, and Katrien Schaubroeck. I should especially like to thank an anonymous referee of this journal for numerous highly useful critical comments on earlier versions of this paper.

Open Access This article is distributed under the terms of the Creative Commons Attribution License which permits any use, distribution, and reproduction in any medium, provided the original author(s) and the source are credited.

\section{References}

Benson P (2005) Taking ownership: authority and voice in autonomous agency. In: Christman J, Anderson J (eds) Autonomy and the challenges to liberalism. Cambridge University Press, Cambridge, pp 101-126

Brandom R (2000) Articulating reasons: an introduction to inferentialism. Harvard University Press, Cambridge/ Mass

Bransen J (1996) Identification and the idea of an alternative of oneself. Eur J Philos 4(1):1-16

Bransen J (2000) Alternatives of oneself. Recasting some of our practical problems. Philos Phenomenol Res 60(2):381-400

Bransen J (2006) Selfless self-love. Ethical Theory Moral Pract 9(1):3-25

Bransen J (2008) Personal identity management. In: Mackenzie C, Atkins K (eds) Practical identity and narrative agency. Routledge, New York, pp 101-120

Bruckner D (2009) Silent prudence. Philos Explor 12(3):349-364

Frankfurt H (1994) 'Autonomy, necessity, and love', in H. Frankfurt, Necessity, Volition, and Love. Cambridge: Cambridge University Press, 1999, pp. 129-141

Frankfurt H (2004) The reasons of love. Princeton University Press, Princeton

Holton R (2001) What is the role of the self in self-deception? Proc Aristot Soc 101(1):53-69

Kalish C (2005) 'Becoming status conscious: children's appreciation of social reality.' Philos Explor 8(3)

Mackenzie C (2008) Imagination, identity and self-transformation. In: Mackenzie C, Atkins K (eds) Practical identity and narrative agency. Routledge, New York, pp 121-145

Moran R (2001) Authority and estrangement. An essay on self-knowledge. Princeton University Press, Princeton

Tugendhat E (1986) Self-consciousness and self-determination. MIT Press, Cambridge/Mass

Wilson T (2002) Strangers to ourselves: discovering the adaptive unconscious. Harvard University Press, Cambridge/Mass

Wittgenstein L (1953/2001) Philosophical investigations. Blackwell Publishing, Oxford

Wolf S (2004) The moral of moral Luck', philosophic exchange. In: Calhoun C (ed) Setting one's moral compass: essays by women philosophers. Oxford University Press, New York 